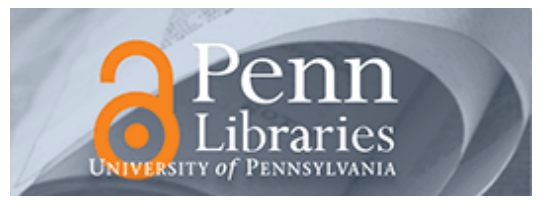

University of Pennsylvania

ScholarlyCommons

Accounting Papers

Wharton Faculty Research

$1-2003$

\title{
Open Versus Closed Conference Calls: The Determinants and Effects of Broadening Access to Disclosure
}

Brian J. Bushee

University of Pennsylvania

Dawn A. Matsumoto

Gregory S. Miller

Follow this and additional works at: https://repository.upenn.edu/accounting_papers

Part of the Accounting Commons

\section{Recommended Citation}

Bushee, B. J., Matsumoto, D. A., \& Miller, G. S. (2003). Open Versus Closed Conference Calls: The Determinants and Effects of Broadening Access to Disclosure. Journal of Accounting and Economics, 34 (1-3), 149-180. http://dx.doi.org/10.1016/S0165-4101(02)00073-3

This paper is posted at ScholarlyCommons. https://repository.upenn.edu/accounting_papers/37

For more information, please contact repository@pobox.upenn.edu. 


\title{
Open Versus Closed Conference Calls: The Determinants and Effects of Broadening Access to Disclosure
}

\author{
Abstract \\ Recent advances in information technology allow firms to provide broader access to their disclosures. We \\ examine the determinants and effects of the decision to provide unlimited real-time access to conference \\ calls (i.e., "open" conference calls). Our evidence suggests that the decision to provide open calls is \\ associated with the composition of a firm's investor base and, to some degree, the complexity of its \\ financial information. We also find that open calls are associated with a greater increase in small trades \\ (consistent with individuals trading on information released during the call) and higher price volatility \\ during the call period.
}

\section{Keywords}

conference call, corporate disclosure, selective disclosure, price volatility, institutional investor

\section{Disciplines}

Accounting 


\title{
Open versus Closed Conference Calls: \\ The Determinants and Effects of Broadening Access to Disclosure
}

\author{
Brian J. Bushee \\ The Wharton School \\ University of Pennsylvania \\ 2400 Steinberg-Dietrich Hall \\ Philadelphia, PA 19104-6365 \\ bushee@wharton.upenn.edu
}

Dawn A. Matsumoto

University of Washington Business School

Box 353200

Seattle, WA 98195

damatsu@u.washington.edu

Gregory S. Miller

Graduate School of Business Administration

Harvard University

Boston, MA 02163

gmiller@hbs.edu

February 2002

We are extremely grateful to Mark Coker, Founder and CEO, BestCalls.com; Stanley Levine, Director of Quantitative Research, First Call Corporation; and IBES for providing us with the data used in this study. We also thank Mary Barth, Phil Berger, Bob Bowen, Donal Byard, Doug Skinner, Ro Verrecchia, Wanda Wallace, Jerry Zimmerman (editor), an anonymous reviewer, and workshop participants at the 2001 Journal of Accounting and Economics conference, the 2001 American Accounting Association annual meeting, the College of William and Mary, Harvard University, Rutgers University, the University of Pennsylvania, and the University of Washington for helpful comments and suggestions. Finally, we thank William Simpson, Senior Statistician at the Harvard Business School, for his econometric advice and Suraj Srinivasan for his research assistance. 
Open versus Closed Conference Calls:

The Determinants and Effects of Broadening Access to Disclosure

\begin{abstract}
Recent advances in information technology allow firms to provide broader access to their disclosures. We examine the determinants and effects of the decision to provide unlimited realtime access to conference calls (i.e., "open" conference calls). Our evidence suggests that the decision to provide open calls is associated with the composition of a firm's investor base and, to some degree, the complexity of its financial information. We also find that open calls are associated with a greater increase in small trades (consistent with individuals trading on information released during the call) and higher price volatility during the call period.
\end{abstract}

JEL classification: M41, M44, G12, G14, G39, K22

Key Words: Conference calls, Corporate disclosure, Selective disclosure, Price volatility, Institutional investors 


\section{Introduction}

Recent advances in information technology have led to dramatic changes in the ability of managers to disseminate information to the capital markets. Firms can now use company websites and/or "webcast" conference calls via the Internet to communicate information immediately, broadly, and inexpensively to all investors. These methods provide investors formerly excluded from live information releases with unlimited access to timely information, which they can then use to execute trades in real-time (Reilly, 2000). These advances have made the decision of how broadly to disseminate voluntary disclosures a key choice in a firm's disclosure policy, with implications for how the market will react to the firm's disclosures. While prior research has examined the decision to provide voluntary disclosures (Healy and Palepu, 2001; Verrecchia, 2001), there is limited evidence regarding the choice and market impact of broadly disseminating disclosures.

We investigate the determinants and effects of the decision to broadly disclose information by focusing on the choice to provide "open" conference calls (i.e. calls that allow unlimited access) to discuss quarterly earnings releases. Despite the low cost and widespread availability of the technology to provide open calls, only $55 \%$ of our sample utilizes it. We obtain a sample of firms that provide unlimited access to their conference calls from BestCalls.com. We then identify firms who provide "closed" calls (i.e. calls that restrict access to invited professionals) using conference call data obtained from First Call.

We hypothesize that the decision to host an open conference call depends on managers' incentives to provide all investors and stakeholders immediate access to information. In our determinants test, we examine whether managerial incentives to provide open calls are related to the composition and demands of the firm's investor base, the complexity of the information 
discussed in a conference call, and the demands of employees for unfiltered information about the company. We find that firms providing open calls have a greater number of shareholders (relative to other firms their size), lower institutional ownership, lower analyst following, and higher average share turnover than closed call firms. These results are consistent with firms opening conference calls to meet nonprofessional shareholders' demands for information. Firms with higher intangible assets are also less likely to provide open calls, consistent with the idea that firms with more complex financial disclosures target the information to more sophisticated users (i.e., financial analysts and institutional investors). These results could reflect endogenous relations between the decision to host open calls and the firm characteristics. However, using lagged values of the firm characteristics produces similar findings, suggesting that the decision to host an open call is a function of firm characteristics in place prior to the decision. In addition, contemporaneous changes in the firm characteristics are generally not statistically different between open and closed call firms, indicating that the results are not driven by changes in firm characteristics subsequent to the decision to host open calls.

Next, we investigate the impact of open conference calls on trading patterns during the call period. These tests provide evidence on whether broader real-time access to information results in greater trading by individual investors, higher price volatility, and/or higher trading volume during open call periods than during closed call periods. Prior research finds that average trade size increases during conference calls, suggesting that larger investors trade during these calls (Frankel, Johnson, and Skinner, 1999). We find that open calls are associated with an increase in small trades (trades of less than $\$ 10,000$ ), suggesting that individual investors exploit their opportunity to trade on information released during open call periods. We also find that open calls are associated with higher price volatility relative to closed calls, but find no effect on 
trading volume. These results indicate that providing individual investors access to conference calls increases the amount of informedness and consensus in the market. Alternatively, it is possible this higher price volatility is due to individual investors' overreacting to information released during the call, a common fear of managers who desire to keep their calls closed (IRB Staff, 2000; NIRI, 2000b).

This paper contributes to our understanding of managers' disclosure choices in a number of ways. While prior research has generally focused on the initial decision of whether to make information available to the capital markets (e.g., Tasker, 1998; Frankel, Johnson and Skinner, 1999), we examine the factors that influence how broadly managers choose to deliver the message. We also provide evidence on the consequences of making information more widely available to the investing public. For example, based on concerns over selective disclosure of information, the Securities and Exchange Commission (SEC) recently passed Regulation Fair Disclosure (Reg FD), requiring all firms to provide open access to any "material" new information. ${ }^{1}$ The controversy surrounding the passage of Reg FD suggests significant uncertainty regarding the consequences of making information widely available. The evidence in this paper helps to resolve this uncertainty.

In the next section we discuss the distinction between open and closed conference calls and describe our dataset. In Section Three, we discuss possible determinants of open conference calls. We also describe the methodology used to test our hypotheses and discuss the results of this analysis. Section Four provides a discussion of the potential impact of open conference calls

\footnotetext{
${ }^{1}$ Regulation FD went into effect on October 23, 2000, after the sample period of our study. The regulation requires that (1) when an issuer intentionally discloses material information, it do so through public disclosure, not through selective disclosure; and (2) whenever an issuer learns that it has made a non-intentional material selective disclosure, the issuer make prompt public disclosure of that information.
} 
on trading patterns during the call along with the methodology and results of this analysis. Concluding remarks are provided in the final section.

2. Open versus closed conference calls

The increased use of conference calls over the past decade has prompted studies examining the factors influencing a firm's decision to host a conference call (Tasker, 1998), the impact of conference calls on trading (Frankel, Johnson, and Skinner, 1999), and the effect of conference calls on analysts' forecasts (Bowen, Davis, and Matsumoto, 2002). During the sample period of these studies, a relatively small number of firms allowed individual investors real-time access to their conference calls (Thompson, 2000). Further, even when a company made their calls available to the public, it was costly to inform individual investors about the dates, times, and call-in numbers. In the last three years, technological innovations have reduced the costs of allowing individual investors to access conference calls. ${ }^{2}$ A 2000 survey by the National Investor Relations Institute (NIRI) indicated $48 \%$ of the firms conducting conference calls were webcasting the calls, allowing a virtually unlimited number of people access to the call (Thompson, 2000).

We obtain data on open conference calls from BestCalls.com. This company does not produce or broadcast conference calls but rather lists free information on open calls from a variety of sources, such as: 1) the lists of broadcasting companies (e.g., Vcall and StreetFusion), 2) company researchers who contact companies to obtain conference call information, and 3) companies themselves posting information to the website. The availability and timing of these calls is generally well-publicized. BestCalls.com often posts the time of the call at least one

\footnotetext{
${ }^{2}$ Companies that host webcast conference calls, such as Vcall, generally charge around $\$ 500$ - $\$ 1,000$ per call (NIRI 2001). Thus, the direct costs of providing calls are likely not material.
} 
week in advance of the call and firms also frequently list their upcoming conference calls on their websites. In addition, BestCalls.com, the broadcast companies, and many firms provide an e-mail reminder function for registered individuals.

Our data from BestCalls.com includes open calls from March 1999 to June 2000. Table 1 provides descriptive statistics on this database. Panel A shows that the vast majority of calls relate to earnings announcements (89\%), consistent with the sample in Frankel, Johnson, and Skinner (1999). For our determinants test, we limit the analysis to live conference calls related to an earnings announcement. We exclude other calls because they are more likely to pertain to an unusual event (e.g. mergers, restructurings). For our tests of trading patterns during calls, we further limit the sample to calls held during trading hours to ensure our results are not driven by differences between regular and after-hours trading. Panel B indicates that webcasts are the more popular form of open conference call, with $85 \%$ of calls being webcast versus $15 \%$ providing telephone-only access. ${ }^{3}$ For live earnings announcement calls, the percentage of telephone-only access increases (to $16.3 \%$ ) while the percentage providing toll-free access decreases (from $57.6 \%$ to $46.5 \%$ ), suggesting that open access is made slightly more costly for live earnings announcement calls.

We use data provided by First Call Corporation to identify closed conference calls. First Call Corporation is a global research network targeted primarily at institutional buy- and sell-side markets. The company provides daily lists of conference calls to its clients and also maintains a database of conference calls for academic use. For our study, conference calls listed on First Call (between March 1999 and June 2000) but not listed on BestCalls.com are identified as firms hosting closed calls. It is possible that some of the conference calls on the First Call

\footnotetext{
${ }^{3}$ Webcast calls are also simultaneously provided via the telephone in many cases. We classify such observations as webcasts because we are interested in the differences between web availability and telephone-only access.
} 
database were open to the public but not listed on the BestCalls.com database; however, any misclassification of open calls as closed will only serve to weaken our tests. ${ }^{4}$

3. Determinants of the decision to provide open conference calls

\subsection{Hypotheses and prior research}

Prior studies examining the determinants of firms' disclosure policies hypothesize that firms engage in disclosure to reduce adverse selection problems and/or expected legal liability costs (see Healy and Palepu, 2001 and Verrecchia, 2001 for reviews of this literature).

Consistent with these theories, Lang and Lundholm (1993) find positive associations between firms' overall disclosure policies (measured using analysts' ratings of disclosure practices) and firm size, firm performance, and recent security issuances; and negative associations with the correlation between earnings and returns. Frankel, Johnson, and Skinner (1999) and Tasker (1998) focus on firms that adopt a specific type of disclosure mechanism - the corporate conference call. Conference calls differ from traditional disclosures in that they allow managers to expand on quarterly earnings releases, qualitatively discuss the prospects of the firm, and respond to questions. Because of these features, Frankel, Johnson, and Skinner (1999) predict and find that firms in high-tech industries and with higher market-to-book ratios and sales growth rates are more likely to host conference calls. Similarly, Tasker (1998) finds that firms are more likely to host conference calls when financial statement informativeness is low.

The dramatic increase in the number of firms providing conference calls in recent years suggests that hosting conference calls has become almost standard practice for most firms (NIRI, 1998; Bowen, Davis, and Matsumoto, 2002). However, during our sample period, some firms

\footnotetext{
${ }^{4}$ We called a sample of 85 firms that were listed as closed and, in each case, a member of the firm's investor relations department confirmed that they did not provide open access to conference calls during our sample period.
} 
chose to restrict access to their conference calls to only selected analysts and large investors. When conference call access is restricted, individual investors receive delayed information filtered through analyst reports and the financial press. Thus, the decision to broaden access to conference calls depends on whether managers have incentives to provide all financial statement users (especially small investors) immediate access to unfiltered information. We test three potential sources of managerial incentives to host open conference calls - the composition and demands of the firm's investor base, the complexity of the information discussed in a conference call, and employee demands for unfiltered information about the company. ${ }^{5}$

Prior research has found evidence consistent with firms responding to investor demands for greater voluntary disclosures (Frost and Pownall, 1994; Botosan and Harris, 2000).

Managers have incentives to respond to investor demands for equal access to disclosure because reduced information asymmetry among investors can lower their cost of capital (Healy and Palepu, 2001; Verrecchia, 2001). In addition, less informed investors would demand broader dissemination practices to avoid the possibility of trading against more informed investors (Wang, 1993). Because of the higher potential for information asymmetry among investors, firms with a more highly dispersed investor base are likely to experience greater pressure from shareholders to broaden their disclosure practices and are more likely to provide open conference calls. As a measure of ownership dispersion, we use the log of the number of shareholders minus the log of the mean number of shareholders in the firm's size decile (LNOWN) (see Table 2 for detailed definitions of variables). ${ }^{6}$

\footnotetext{
${ }^{5}$ It is also possible that litigation costs could differ between open and closed calls. However, in both cases, the firm is disclosing material information to the market. Under existing fraud-on-the-market rules, individuals can sue regardless of whether they heard the information directly or not. Thus, litigation costs are unlikely to differ between the two types of calls.

${ }^{6}$ We also size-adjust this variable to ensure that it does not proxy for firm size. We form size deciles using total sales. We obtain similar results when we use total assets to define the size deciles and weaker results when we use the market value of equity. In the latter case, there is a higher level of multicollinearity in our model because we
} 
In contrast, firms with a higher percentage of shares held by institutions and/or a higher level of analyst following likely receive less pressure to host open calls since these capital market participants are generally invited to participate in the calls (irrespective of the company's policy with regard to the general public and the media). Moreover, these information intermediaries could actually prefer that information not be broadly disseminated because they are concerned about either a decline in the quality of the information communicated or a loss of their informational advantage (NIRI 2000a). Thus, firms with higher institutional ownership and/or higher analyst following likely perceive less benefit to broadening access to their calls. We include the percentage of institutional ownership (PIH) and level of analyst following (NAL) to test for this effect.

Firms whose shares are frequently traded also likely face pressure from shareholders to disclose information. Investors who trade frequently are concerned about liquidity (Bushee and Noe, 2000) and broader information dissemination practices increase liquidity by reducing the information asymmetry between investors. Thus, firms with high share turnover face stronger demands to provide open calls. We proxy for this effect with the firm's mean share turnover (MTURN), measured as mean monthly trading volume deflated by mean shares outstanding during calendar year 1999.

In addition to investor demands, the decision to broaden disclosure practices is likely influenced by anticipated investor reactions to the information. Providing unsophisticated investors unfiltered access to information increases the likelihood that such investors will form

include market value of equity as a control variable for size. We follow a similar approach with the number of employees variable (discussed later).

${ }^{7}$ It is also possible that firms that are neglected by analysts and institutions have greater incentives to open conference calls to individual investors to broaden their investor audience and overcome the lack of information intermediaries (Healy, Hutton, and Palepu, 1999). This explanation would again predict a negative relation between opening conference calls and the percent of institutional ownership and analyst following, although for a slightly 
diverse opinions (Barron, Byard, and Enis, 2001). If these investors immediately trade based on these opinions, the firm could experience an increase in stock price volatility. Given that the company is under intense scrutiny by the market during the conference call, higher stock price volatility during this period is more likely to leave the impression that the firm's stock price is generally volatile, potentially increasing the perceived riskiness of the firm (Froot, Perold, and Stein, 1992) and deterring investors from trading in the stock (NIRI, 1999). ${ }^{8}$ Thus, we predict that firms with complex information disclosures will likely prefer closed calls to ensure the information is filtered through more sophisticated sources, such as financial analysts, reducing the potential for misinterpretation and excess volatility. ${ }^{9}$

We include proxies for several different sources of complex financial disclosures. First, firms with a complex business model will have more complicated financial disclosures because the information required to explain current performance and to provide indications of future performance is likely to be technical in nature and easy to misinterpret without training or a background in the field. ${ }^{10}$ As a proxy for firms with complex business models, we use an indicator for membership in a high-tech industry (DHTECH). ${ }^{11}$ Such firms frequently experience rapid change and innovations that increase the complexity of the information

different reason (i.e., to influence the type of investor you attract rather than to respond to demands of your existing shareholder base).

${ }^{8}$ As an example of the level of attention that a firm receives during a conference call, a recent Washington Post article reported that Cisco's May 2001 quarterly earnings conference call attracted 34,000 listeners (Vinzant, 2001).

${ }^{9}$ Managers of firms with complex financial disclosures could also choose to restrict access due to proprietary cost concerns. If competitors can obtain more proprietary information through listening to an open call than they could through reading a filtered analyst report of the call, then managers wishing to disclose proprietary information have incentives to host closed calls.

${ }^{10}$ An alternative explanation is that firms with more complex business models would prefer to allow unsophisticated investors access to the conference call so that they receive disclosure directly from the firms rather than filtered through analyst reports. This would be the case if such firms believed the filtering mechanism would either reduce the richness/content of the information provided or potentially misinterpret the information.

${ }^{11}$ SIC codes classified as DHTECH include: Drugs (2833-2836); Electric Distribution Equipment (3612-3613); Electrical Industrial Apparatus (3621-3629); Household Audio \& Video Equipment (3651-3652), Communications Equipment (3661-3669); Electron Tubes (3671); Printed Circuit Boards (3672); Semiconductors \& Related Devices 
provided and the difficulty in valuing the firm (Lev and Zarowin, 1999). We also include a proxy for volatility in operating performance, measured as the standard deviation of the firm's seasonally-differenced quarterly revenue (VREV) over the past 16 months. Volatility in operating performance likely reflects greater unpredictability in the underlying business model and greater difficulty in interpreting the future implications of current events.

Second, firms that participate in frequent and/or substantial financial transactions, such as mergers, acquisitions, and divestitures, generally have more complex information to communicate. We include the percentage of recorded intangible assets (INTAN) as a measure of the importance of such information in the firm's reporting environment (Barth, Kasznik, and McNichols, 2001). These recorded intangibles consist predominately of items created through financial transactions (e.g., goodwill, purchased intangibles, franchises), whose valuation implications are likely more difficult to assess than those of tangible assets such as property, plant, and equipment.

Finally, firms with low financial statement informativeness are likely to use conference calls as a means of supplementing mandatory accounting disclosures to communicate valuerelevant information to market participants (Tasker, 1998). Firms with low financial statement informativeness, which Tasker (1998) defines as the extent to which current accounting rules capture the value of the firm, have a greater proportion of their value in economic assets that are not recorded by the accounting system (e.g., the value of R\&D investment, growth opportunities, etc.). Because managers of such firms must communicate why the accounting numbers are not reflective of firm value, while providing information that will serve such a role, they are more likely to target their calls to sophisticated investors only. We include two proxies for the 
informativeness of the firm's accounting information. First, following Tasker (1998), we use the book-to-market ratio (BP). Because this measure can also proxy for risk, real options, and/or mispricing, we include a second proxy, the industry-level R-square (IRSQ) from an ERC regression of market-adjusted returns on changes in and levels of annual earnings (Francis and Schipper, 1999; Matsumoto, 2002). ${ }^{12}$ The lower the book-to-market ratio and the industry-level R-square, the more difficult it is to assess the valuation implications of the firm's mandatory disclosures. ${ }^{13}$ In summary, we predict that firms in high-tech industries and firms with higher revenue volatility, a greater proportion of intangible assets, a lower book-to-market ratio, and a lower industry-level R-square will be less likely to provide open calls to investors.

In addition to reducing the cost of capital, firms can also potentially reduce transactions costs with other stakeholders by broadening disclosure to these user groups. Miller and Piotroski (2000) find that firms with large numbers of employees provide more voluntary disclosure to communicate an expected increase in performance prior to its recognition in an earnings announcement. They argue that, as the employee base grows more diffuse, internal communication mechanisms are viewed as less credible, especially when a manager's credibility is in question due to recent poor performance. In such a case, external disclosures are important to employees as a source of credible information about the firm, increasing the manager's incentives to provide open calls. While most firms in our sample are not currently facing such credibility issues, informal discussions with investor relations officers indicate that employees frequently listen to conference calls and view them as a useful forum for learning about issues

\footnotetext{
${ }^{12}$ We use an industry-specific measure because computing firm-specific R-squares would greatly reduce the sample size. Moreover, Biddle and Seow (1990) find that industry membership explains much of the firm-specific variation in ERC's. We compute the R-square using observations from the prior three fiscal years (1997-9).

${ }^{13}$ Low financial statement informativeness is likely related to both complex business models and the level of financial transactions (e.g. mergers, divestitures). However, the correlations between BP, IRSQ, and our proxies for these other measures of complexity (see Panel C of Table 3 ) indicate that each variable captures a somewhat different form of complex financial disclosure.
} 
facing the firm. This suggests that firms with larger numbers of employees, relative to other firms their size, face greater incentives to host open calls. We use the log of the number of employees minus the log of the mean number of employees in the firm's size decile as a proxy for employee demand for credible information (LNEMP).

Finally, we include two additional variables to control for other possible determinants of firms' disclosure practices. We include firm size, measured as the log of the firms' market value (LMV), because prior work has found that firm size is related to disclosure practices (Lang and Lundholm, 1993; Frankel, Johnson, and Skinner, 1999). We also include the age of the firm (LTIME), measured as the log of the number of months the firm has been listed on CRSP, because younger firms are likely to have less entrenched disclosure policies and hence could be more inclined to adopt new technologies.

The prior discussion does not distinguish between open conference calls provided via webcasts and those provided via telephone access only. Webcasts potentially allow broader access to information because, as Table 1 indicates, a majority of telephone dial-in numbers are not toll-free for earnings-related conference calls. Thus, the individual must bear some cost in order to listen to such calls. In addition, webcasts are potentially more visible to individual investors who are attuned to finding and receiving information via the Internet because of on-line trading. To provide descriptive evidence on any potential differences between these two methods of providing open calls, we also separately analyze the choice to provide webcast versus telephone-only access.

The prior discussion also assumes the firm's shareholder structure and business complexity are exogenously determined; i.e., managers decide on the optimal disclosure strategy given their current environment. It is possible, particularly in the case of shareholder structure, 
that disclosure strategies partially determine these firm characteristics. As with most empirical studies, it is difficult to infer causality from association tests. In sensitivity analyses, we attempt to investigate this issue by examining the effect on our results of using lagged independent variables and contemporaneous changes in determinants in our analysis. Nevertheless, we recognize the limitations of this analysis in determining causality and our results should be interpreted accordingly.

\subsection{Results}

\subsubsection{Univariate analysis}

For our determinants analysis, we classify each firm as providing open or closed conference calls based on calls made during 1999-2000. Firms that initially appear on the First Call database as closed calls but subsequently appear on the BestCalls.com database with open calls are classified as open call firms for the purpose of this analysis. No firm switched from open calls to closed calls.

We obtain data for our explanatory variables from the 1999 CRSP Monthly and Daily Files, the 1999 Compustat Annual and Quarterly Data Files, the Spectrum database of institutional holdings, and the IBES database of analysts' earnings forecasts. We measure the variables using the most recent fiscal year provided on Compustat (fiscal years ended June 1999 - May 2000) and from the calendar year 1999 for CRSP, Spectrum, and IBES (see Table 2). The final sample includes 3,274 firms: 1,799 that host open calls and 1,475 that host closed calls.

Table 3, Panel A presents descriptive statistics on the firm characteristics of open and closed call firms. Although we use logged values for some variables in our primary analysis (LNOWN, LNEMP, LMV, LTIME), we report raw values in this table for ease of interpretation. 
In univariate comparisons of open and closed call firms, all of the proxies for shareholder demands are significantly different in the predicted direction (e.g., greater number of shareholders, lower institutional ownership, lower analyst following, and higher share turnover for open call firms). Among the proxies for complexity of information and demands of other stakeholders, only the proxy for financial transaction complexity (recorded intangibles) is significant in the predicted direction; differences for the other proxies are either insignificant or contrary to our predictions. However, Panel C of Table 3 shows that many of the variables are significantly correlated with the control variables (LMV and LTIME) and the other explanatory variables. Thus, it is difficult to draw conclusions based solely on the univariate analysis. ${ }^{14}$

Panel B of Table 3 provides mean and median comparisons between firms providing webcasts and those providing telephone-only access. In this sample of 1,799 open call firms, 1,575 firms provide webcasts and 224 firms provide telephone-only access. Firms using webcasts tend to have lower institutional ownership and higher share turnover than telephoneonly firms, consistent with webcasts being a more accessible form of open call for individual investors. In addition, webcast firms tend to be younger firms in high-tech industries with lower industry R-squares from an ERC regression. However, none of the other variables are significantly different between webcast and telephone-only firms.

\subsubsection{Logit analysis}

We model the probability of hosting an open versus a closed conference call as a function of the above-mentioned firm characteristics using a logistic regression:

\footnotetext{
${ }^{14}$ To test for the presence of harmful multicollinearity, we sequentially estimate the logit model with one variable omitted each time. None of the significant results change when variables are dropped from the model. We also estimate the model using OLS and compute variance inflation factors (VIF's). None of the VIF's are greater than 1.6, suggesting that our results are not affected by harmful multicollinearity (for which Kennedy, 1998, cites a benchmark VIF of 10).
} 


$$
\begin{gathered}
\operatorname{Prob}(\text { Open })=F\left(\beta_{0}+\beta_{1} L_{N O W N_{i}}+\beta_{2} P_{I H}+\beta_{3} N A L_{i}+\beta_{4} M T U R N_{i}+\beta_{5} \text { VREV }_{i}+\beta_{6} \text { BP }_{i}\right. \\
\left.+\beta_{7} I R S Q_{i}+\beta_{8} I N T A N_{i}+\beta_{9} \text { DHTECH }_{i}+\beta_{10} L N E M P_{i}+\beta_{11} L M V_{i}+\beta_{12} L T I M E_{i}+\varepsilon_{i}\right)
\end{gathered}
$$

where $F\left(\beta^{\prime} X\right)=\frac{e^{\beta^{\prime} X}}{1+e^{\beta^{\prime} X}}$

Table 4 presents the results of this analysis. Coefficients and p-values (two-tailed) are reported in the first column. An estimate of the marginal impact represented by the coefficient is presented in the second column. This estimate represents the change in probability of providing an open call that results from moving from the first to third quartile of each independent variable's distribution. It is computed by multiplying the variable's interquartile range by the effect of a one-unit change in the variable suggested by the coefficient. ${ }^{15}$

Firms with higher institutional ownership (PIH) are significantly less likely to provide open calls. This factor is the strongest determinant of open versus closed calls with a 0.129 difference in probability between the first and third quartiles of its distribution. Firms with more disperse ownership (relative to other firms their size) (LNOWN), lower analyst following (NAL), and higher share turnover (MTURN) are also significantly more likely to provide open calls. These results support the prediction that investor demands for open access to conference calls influence the likelihood of providing open calls.

We find mixed evidence that firms with more complex financial disclosures are less likely to host open calls. Supporting this prediction, firms with higher levels of reported intangibles (INTAN) are significantly less likely to provide open calls, indicating that firms with a high level of financial transactions prefer the information to be filtered through analysts. In

\footnotetext{
${ }^{15}$ The effect of a one-unit change in an independent variable is calculated by multiplying the estimated coefficient by $e^{\beta^{\prime} X} /\left(1+e^{\beta^{\prime} X}\right)^{2}$, where $\beta^{\prime} X$ is computed at the mean values of independent variables (Greene, 2000). For the indicator variable DHTECH, the marginal impact is the difference in probability when the variable equals one versus when it equals zero, evaluated at the mean of the other variables.
} 
addition, the coefficient on the industry-level R-square (IRSQ) is positive and marginally significant $(\mathrm{p}$-value $=0.066)$, consistent with firms restricting access to calls when financial statement informativeness is low. However, our other proxy for financial statement informativeness - the book-to-price ratio (BP) — is not significantly related to providing open calls, possibly due to the fact that conference call firms tend to have relatively high market-tobook ratios (Tasker, 1998; Frankel, Johnson, and Skinner, 1999). Contrary to our predictions, firms with greater volatility of revenue (VREV) and firms in high tech industries (DHTECH) are more likely to host open calls. This finding suggests that, for firms with complex business models, the benefits of directly communicating to all investors the supplemental information needed to interpret the firm's recent earnings performance outweigh the costs of unsophisticated investors misinterpreting the information.

We also find an insignificant association between the number of employees, relative to firm size, (LNEMP) and the decision to host open calls, suggesting that the decision to provide open calls is not impacted by the need to credibly communicate to employees. This finding is likely due to the fact that the decision to provide open calls is a policy choice, while the need to credibly communicate to employees varies with firm performance. Both control variables, firm size (LMV) and time listed (LTIME) are not significantly associated with the decision to provide open calls.

Overall, the model has statistically significant explanatory power $\left(\chi^{2}=217.3\right.$, p-value $<$ 0.001). Using a 50\% cut-off point to classify firms (i.e., classifying firms with predicted values $>50 \%$ as "open calls") correctly classifies firms as open $66 \%$ of the time. A naïve model that classifies all firms as open is correct $55 \%$ of the time $(1,799 \div 3,274=55 \%)$. Thus, significant differences exist between open and closed call firms. 
In the third and fourth column of Table 4, we examine whether our variables explain the probability of providing open conference calls via webcasts versus providing telephone-only access. The results suggest that not only are firms with higher institutional ownership (PIH) and higher analyst following (NAL) less likely to provide open calls, when they do make them available, it is generally done via telephone, which is a less "individual investor friendly" method of dissemination. Younger firms (LTIME) are significantly more likely to use a webcast, possibly because these firms are more inclined to embrace new technology. Finally, larger firms (LMV) are more likely to use webcasts, perhaps the result of more active investor relations departments. ${ }^{16}$

\subsubsection{Sensitivity analyses}

As mentioned earlier, the fact that our explanatory variables are measured contemporaneously with the conference calls raises the possibility of endogeneity between the decision to provide open calls and our determinants variables. In other words, the significant associations documented above could reflect managers making the decision to host open conference calls based on pre-existing firm characteristics and/or firm characteristics changing in response to the decision to host open calls.

To provide more evidence on whether the initial decision to provide open calls is a result of pre-existing firm characteristics, we estimate the logit regression with lagged values of the explanatory variables, measured using fiscal year 1997 Compustat and CRSP data and PIH and

NAL at the end of 1997. Because most firms began providing open calls relatively recently,

\footnotetext{
${ }^{16}$ The web vs. phone analysis omits firms that held closed calls, creating a potential selection bias in this test. Ideally, we would address this problem with a nested multinomial logit model to jointly estimate the open vs. closed decision with the web vs. phone decision. However, the model does not converge, likely due to the small number of observations that provide phone-only access. Instead, we estimate a multinomial logit with three ordered groups: web, phone, and closed. The results are similar to the open vs. closed results. We also separately estimate web vs. closed and phone-only vs. closed. The web vs. closed results are similar to the open vs. closed results, whereas only
} 
these lagged variables likely represent firm characteristics in place prior to the decision to provide open calls. For the open vs. closed call decision, our results are essentially the same in sign and significance level as in Table 4, except for LNOWN and DHTECH, which are insignificant. These findings suggest that our results are not solely driven by changes in determinants after the decision to provide open calls was made, but rather reflect firm characteristics in place prior to the decision.

Next, we examine the extent to which our results reflect changes in firm characteristics after 1997. We estimate the logit model with the open vs. closed decision modeled as a function of changes in the firm characteristics between 1997 and 1999 (with the exception of the change in time listed, which we dropped because it would be the same for all firms). The results indicate that open call firms experience smaller increases in institutional ownership and number of employees and larger increases in market value than closed call firms between 1997 and 1999 . No other change variables are significant. Thus, with the possible exception of $\mathrm{PIH}$, it is unlikely that the results in Table 4 are driven by changes in firm characteristics subsequent to the decision to host open calls. While these analyses do not formally correct for any statistical biases due to endogeneity, they do provide additional evidence that managers made the decision to host open calls based on pre-existing firm characteristics.

We also examine the potential impact of the small number of firms (350) that switch from closed calls to open calls during the sample period. Recall that these "switching firms" are considered open call firms for the purpose of the primary analysis. We estimate the logit model with 1) switching firms deleted from the analysis, 2) switching firms considered closed call firms instead of open call firms, 3) a multinomial model that placed switching firms as a separate telephone only limits the power of any separate analysis of this decision. 
group between firms that are always open and those that are always closed. The results are essentially the same as our primary analysis. Thus, our results are not sensitive to our classification of the firms that switched disclosure policy during the sample period.

We further examine the firms that switch to determine whether the change in disclosure policy is due to changes in firm characteristics or to the late adoption of open call technology. First, we estimate two cross-sectional logit models similar to Table 4 to examine how switching firms differ from firms that are open or closed throughout the sample period. Second, we estimate logit regressions to compare yearly changes in the explanatory variables between switching firms and firms that remain closed throughout (i.e. did not choose to switch). ${ }^{17}$

Overall, the results of these analyses indicate that switching firms are 1) between open and closed firms on many key firm characteristics, 2) generally larger in size than both open and closed call firms, and 3) not experiencing changes in determinants different than those for closed firms. We interpret this evidence as indicating that switching firms are merely large firms that are late adopters of open call technology rather than firms that change their policy in response to a dramatic change in firm characteristics.

4. Market effects of open conference calls 4.1 Hypotheses and prior research

\footnotetext{
${ }^{17}$ An important problem with examining changes in determinants for switching firms is that we do not know when the decision was made to switch to open calls. Ideally, we would want to measure changes in determinants leading up to the decision to switch. However, our data only provides the date on which the first open call was made, which could be one or two quarters after the decision to switch was made. Another problem is that we have a fairly short time-series of observations ( 16 months) while many of our determinants are only available on an annual basis. These problems reduce our power to detect any short-term changes in determinants that trigger a decision to switch.
} 
We examine the impact of open calls on three metrics of trading behavior during the call period: trade size, price volatility, and trading volume. This analysis is conducted at the individual conference call level, using only calls conducted during trading hours.

Open conference calls allow smaller investors greater access to information about the firm. During the period when conference calls were generally restricted to larger shareholders and sell-side analysts, Frankel, Johnson, and Skinner (1999) find evidence consistent with conference calls placing smaller investors at an informational disadvantage. Regulation FD was specifically implemented to address small investors' concerns by eliminating selective disclosure of material information to certain capital market participants. However, to date, there has been little evidence that individuals' trading behavior is a function of their access to conference calls. We investigate whether open calls result in greater trading activity by smaller investors, relative to closed calls. We define the percentage of small trades (SMTRADE) as the number of small trades during the call period divided by the total number of trades during the period (see Table 2 for variable definitions). Following Lee (1992), we obtain the firm's opening price at the beginning of the trading period and compute the largest number of round lot shares that is less than or equal to $\$ 10,000$. We define a small trade as any trade less than or equal to this lot size. ${ }^{18}$ If providing direct access to information encourages trading by individual investors, we would expect to see a larger number of small trades in open call periods compared to closed call periods.

\footnotetext{
${ }^{18}$ We use a dollar-value definition because proxies based solely on trade lot size do not reflect differences in stock prices (Lee, 1992; Lee and Radhakrishna, 2000; Bhattacharya, 2001). However, we conducted the analysis using a cut-off of 1,000 shares for small trades (as in Cready, 1988) and found similar results. We also conducted the analysis using a \$5,000 threshold and our results are qualitatively similar, although somewhat weaker. The lower threshold results in a significant number of zero observations because of the limited trading period (75 minutes) being investigated. Zero observations are particularly problematic for our changes analysis (see 4.2.2).
} 
We also examine the effect of open conference calls on price volatility and trading volume. Although managers have expressed concerns over potential increases in volatility and trading volume as a result of allowing individuals access to their calls, empirical evidence of such an increase has not been previously demonstrated. ${ }^{19}$ Prior analytical research suggests that greater informedness is associated with greater price volatility and trading volume during an information release (Holthausen and Verrecchia, 1990). Allowing a larger number of investors immediate access to new information through open calls should increase the overall level of informedness during the calls. This effect is supported by Barron, Byard, and Enis (2001), who find that non-professional investors use and interpret disclosures differently than professionals, providing a richer set of analyses to the market. These findings suggest that the informedness effect of open calls should result in increased price volatility and trading volume.

Providing open calls could also affect the degree of consensus among market participants. If individuals are less likely to draw similar conclusions from information presented during conference calls, open calls could exhibit less consensus among participants than closed calls, which cater to a more homogeneous audience (Barron, Byard, and Enis, 2001). Less consensus during open calls should produce higher trading volume, reinforcing the informedness effect (Barron, 1995; Bamber and Cheon, 1995; Bamber, Barron, and Stober, 1997). It should also result in lower volatility, contrary to the informedness effect (Holthausen and Verrecchia, 1990). However, while the consensus among those receiving information is likely higher for closed calls versus open calls, it is not clear that the consensus among all market participants is higher during closed calls since individual investors are essentially provided with

\footnotetext{
${ }^{19}$ As a recent Investor Relations Business article states: “The problem is not so much that the public won't understand the scope of information companies are forced to release, but they will sell their shares as a result of it." (IRB Staff, 2000). This concern over the ability of small investors to process complex financial information is not
} 
no information during these calls. To the extent that uninformed individual investors trade during a closed call period, the degree of consensus could actually be lower during a closed call period than during an open call period, where all traders have access to the same information. Because uninformed trading by individual investors during a closed call is likely to mitigate the differences in consensus between open and closed calls, we expect the informedness effect to dominate, resulting in an increase in both trading volume and volatility during open calls.

We examine the association between open calls and two measures of price volatility. The first is the difference between the highest and lowest price during the conference call period, scaled by the low price (HI_LO) (similar to the measure in Wiggins, 1991 and Frankel, Johnson, and Skinner, 1999). The second measure is the coefficient of variation; i.e. the standard deviation of price scaled by the mean price during the conference call window (CVPRC). We examine the association between open calls and trading volume using the log of total shares traded during the conference call window (LTVOL), consistent with Frankel, Johnson, and Skinner (1999).

\subsection{Results}

\subsubsection{Descriptive Statistics}

For our analysis of the effects of open conference calls on trading behavior, we first identify the scheduled start of the conference call from the BestCalls.com and First Call databases. Following Frankel, Johnson, and Skinner (1999), we define the conference call period as beginning 15 minutes prior to the scheduled start of the call and ending 60 minutes

new. Similar concerns motivated the SEC's proposal to allow two-tiered financial reporting (see Bushman, Gigler, and Indjejikian, 1996). 
after the start. ${ }^{20}$ Figure 1 provides a timeline that depicts the measurement period. Using data from the Trade and Quote (TAQ) database, we measure each of our variables - SMTRADE, HI_LO, CVPRC, and LTVOL - during this period (see Table 2).

Table 5, Panel A presents descriptive statistics on the mean and median market effects of open and closed conference calls. Open calls have a significantly higher percentage of small trades during the call period (trades less than $\$ 10,000)$ than closed calls $(66 \%$ versus $58 \%)$, suggesting a higher level of trading activity by small investors in open calls. To provide further descriptive evidence, we examine the proportion of medium trades (MDTRADE), defined as trades between $\$ 10,000$ and $\$ 50,000$, and large trades (LGTRADE), defined as trades greater than $\$ 50,000$. Both of these trade sizes are significantly greater for closed calls than for open calls, indicating that larger investors are more active traders during closed call periods. Next, Panel A shows that both the difference between the high and low price (HI_LO) during the conference call window and the coefficient of variation of price (CVPRC) are significantly higher when calls are open rather than closed. However, trading volume (LTVOL) during the conference call period is significantly higher for closed calls than for open calls during the call period. Thus, the descriptive statistics indicate that open call firms have higher price volatility and lower trading volume during conference call periods.

Panel B of Table 5 presents means and medians for open conference calls that are webcast and those that are provided via telephone only. The panel shows few significant differences between the two methods of providing open calls, with the exception of a higher median CVPRC and lower median LGTRADE for webcasts.

\footnotetext{
${ }^{20}$ The database only provides a scheduled beginning time. It is possible that some calls start prior to the scheduled time. Thus, we begin the period 15 minutes prior to ensure we capture the beginning of the call period. The database does not provide an ending time. However, anecdotal evidence in Frankel, Johnson, and Skinner (1999) suggests that most calls are completed within 60 minutes.
} 


\subsubsection{Changes analysis}

Our previous analysis of the determinants of open conference calls suggests that there are differences in firm characteristics between firms that provide open calls and firms that do not. We use two approaches to control for these differences when comparing market reactions between open and closed calls. First, we conduct a changes analysis that uses the firm as its own control. Second, we use maximum likelihood estimation to jointly estimate the determinants of the decision to host open or closed calls with the market effects during the call period.

In the changes analysis, we compute the value of each of the variables during a control period and subtract this amount from the value computed during the conference call window. ${ }^{21}$ The control period used is approximately the same 75-minute period on the previous trading day (see figure 1)..$^{22}$ Panel A of Table 6 presents tests of differences in mean and median changes in market effect variables between open and closed calls. Tests of means are based on two-sample t-tests with adjustments for unequal variances where appropriate. Tests of medians are based on Wilcoxon rank-sum tests. All p-values are two-tailed. The panel shows that the average increase in small trades $(\triangle \mathrm{SMTRADE})$ is $10.1 \%$, which is significantly greater than the $1.4 \%$

\footnotetext{
${ }^{21}$ A difference in the proportion of small trades (SMTRADE) during the conference call and control periods could be due to either a change in the number of small trades or a change in the number of total trades. Accordingly, we compute a percentage change in small trades between the two periods ( $\triangle$ SMTRADE), defined as the number of small trades during the conference call window less the number of small trades during the control window, divided by the number of small trades during the call window. The variables $\triangle$ MDTRADE and $A$ LGTRADE are defined similarly.

${ }^{22}$ We do not use either of the two 75-minute periods immediately preceding the call period as the control because these periods are not available for calls early in the trading day and because the release of the earnings announcement often happens in these periods. However, the results are similar, though slightly weaker, if we do use these periods as controls. We also used approximately the same 75 -minute period one week prior and the median of all 75 -minute periods during the trading day one week prior as control periods, in addition to periods subsequent to the call period $(+2,+3,+4$, and +19$)$. We obtain the same results in terms of signs and significance using these control periods.
} 
increase in small trades for closed calls. This result suggests that individual investors exploit their access to information in open calls by trading during the call period.

An examination of medium and large trades sizes ( $\triangle \mathrm{MDTRADE}$ and $\triangle \mathrm{LGTRADE})$ indicates a large percentage increase in both these trade size groups for open and closed calls, consistent with the results of Frankel, Johnson, and Skinner (1999) that trade size increases during conference calls. However, the differences between open and closed calls are not significant. Thus, while closed calls have a significantly higher level of medium and large trade sizes relative to open calls, the change in medium and large trades during the call period is not significantly different between the two groups.

The volatility of price also increases during conference call periods (compared to the control period), but more so for open calls than for closed calls. Changes in the magnitude of the difference between high and low prices ( $\triangle \mathrm{HI} L \mathrm{LO})$ and the coefficient of variation ( $\triangle \mathrm{CVPRC}$ ) are both significantly higher for open calls than for closed calls. ${ }^{23}$ Finally, the change in total volume ( $\triangle \mathrm{LTVOL})$ does not increase to a greater extent during open versus closed calls. Using the Holthausen and Verrecchia (1990) model, these results suggest that open calls are associated with more informedness and greater consensus, as these two effects unambiguously produce higher volatility, but result in conflicting effects on volume. The greater consensus during open calls likely stems from the fact that open calls allow everyone to form opinions based on the

\footnotetext{
${ }^{23}$ The finding of higher volatility for open calls raises the question of whether the volatility is due to overreactions by unsophisticated investors, consistent with the concerns of some managers (IRB Staff, 2000; NIRI, 2000b). It is not apparent what form the "overreaction" would take (i.e. when the negative autocorrelation in returns should appear), so we test for negative autocorrelation in returns on a trade-by-trade basis within the call period and between the call period as a whole and subsequent 75 -minute periods during the day and into the next day. In no case do we find significant negative autocorrelation in returns for either open call firms or closed call firms. Thus, it is likely that the greater volatility observed during open call periods reflects changes in informedness and consensus in price formation rather than overreaction by small traders.
} 
same information release, whereas closed calls force individual investors to form opinions based on pre-call information only.

Panel B of Table 6 tests for differences in mean and median changes in market effect variables between webcast and telephone-only calls. If the method by which a firm makes their call broadly available impacts individual investor participation in the call, the effects on trading behavior will differ between the two methods. The panel shows that none of the market effect variables are significantly different between webcast and telephone-only conference calls. However, given the relatively small number of observations with telephone-only access, the lack of results could be due to a lack of power.

\subsubsection{Maximum Likelihood Estimation}

As discussed previously, the fact that firms choose whether to provide open or closed calls could lead to a potential self-selection bias. Such a bias could indicate that firms with open calls would have higher levels of inter-day price variation and small trades even absent the choice to host open calls. ${ }^{24}$ In the prior section, we control for this potential bias by subtracting the level of the same variable measured 24 hours prior to the conference call, using the firm as its own control. However, if the self-selection were associated with differing levels of these variables during the conference calls, but not at any other time, our changes methodology would not provide an effective control for this self-selection.

To control for self-selection, we use full information maximum likelihood estimation (MLE) (see Greene, 1998 and 2000; Kennedy, 1998). This analysis jointly estimates the decision to provide open calls (the selection model) and the effect of open calls on our market effects variables (the market effects model). This joint estimation is performed separately for 
each of our market effect variables: SMTRADE, MDTRADE, LGTRADE, HI_LO, CVPRC, and LTVOL. Because we have only one observation for the selection model for each firm, we use the average of the market effect variables across all call observations for firms with more than one conference call. ${ }^{25}$ We weight the MLE to reflect such averaging. This test's data requirements reduce our sample to 1,380 firm-call observations, of which 680 are open calls and 700 are closed calls. The main reason for the reduction in the number of firm observations is that the determinants sample in Table 4 includes all live open and closed calls related to earnings announcements while the market effects sample uses only live conference calls held during trading hours.

The selection model includes all of the variables used in the determinants test (see equation (1)). The market effects variables are modeled as a function of an indicator variable (OCALL) that equals one if the call is open and equals zero otherwise, as well as those determinants variables that could possibly have a direct effect on trading. We identify the following variables with the potential to directly affect our trading variables: number of owners (LNOWN), share turnover (MTURN), institutional ownership (PIH), book-to-price ratio (BP), and firm size (LMV). The remaining variables are unlikely to have a direct effect on trading patterns. The indirect effect of all the determinants variables is captured in the joint estimation process (e.g., the effect of analyst following on the decision to host open calls and its resulting impact on trade size).

Table 7 presents the MLE estimation results. We present only the market effects model because the results of each jointly-estimated selection model are similar to those reported in

\footnotetext{
${ }^{24}$ For example, this could be the case if these firms systematically choose disclosure policies that, in general, lead to high levels of these variables. Maddala (1986) and Greene (2000) provide thorough discussions of the causes and implications of self-selection biases.
} 
Table 4. ${ }^{26}$ Panel A presents the results using the level of the dependent variables while Panel B presents the results using the change in the dependent variables from the control period (as described in section 4.2.2). The results of these analyses are similar to those reported earlier. Open calls are associated with a significantly greater proportion of small trades and a significantly greater increase in small trades during the call period. The level of price volatility is significantly higher during open calls relative to closed calls; however, the change in price volatility is only marginally higher during open calls relative to closed calls ( $p$-value $=0.073$ two-tailed, or 0.037 one-tailed, in the $\Delta \mathrm{HI}$ LOO model and p-value $=0.125$ two-tailed, or 0.063 one-tailed, in the $\triangle$ CVPRC model). Finally, both the level of and the change in trading volume is not significantly different between open and closed calls.

We also ran this analysis on the comparison of webcast and telephone-only open calls. Similar to our initial analysis, we do not find significantly higher proportions of small trades, price volatility, or trading volume for calls that are webcast versus calls that are provided on a telephone-only basis (not reported).

\subsubsection{Sensitivity Analysis}

We perform a number of sensitivity checks on the above analysis (not reported). To ensure that our results are not sensitive to the choice of control variables included in the market effects model, we also perform the estimation with 1) the full set of determinants variables repeated as control variables in the market effects model and 2) no control variables in the market effects model. With the full set of controls repeated in the market effects model, the

\footnotetext{
${ }^{25}$ We also performed the analysis using a randomly-selected conference call observation for each firm and using all call observations. These alternative approaches yielded similar results.

${ }^{26}$ The only exceptions are VREV and LMV. The coefficient on VREV is generally insignificant (as opposed to being positive and significant as in Table 4) and the coefficient on LMV is positive and significant (as opposed to being insignificant). These two variables are highly correlated with other variables in the model and it is likely that multicollinearity has a greater impact in the smaller sample.
} 
MLE yields similar results for all market effects except for LGTRADE, where the MLE did not converge. With no controls in the market effects model, the MLE yields similar results for all market effects except for $\triangle \mathrm{HI} L \mathrm{LO}$ and $\triangle \mathrm{CVPRC}$, where the MLE did not converge. In the three cases where the MLE did not converge, we use the Heckman two-step procedure (see Greene $1998,2000)$ and find similar results to those presented in Table $7 .^{27}$

Puhani (2000) reviews the simulation literature on joint estimation of selection models and concludes that, in the presence of multicollinearity, OLS provides more robust estimates than either the MLE or Heckman estimators. We compute the variance inflation factors (VIF's) for each regression and find no instances of VIF's greater than 2.2, suggesting that multicollinearity is unlikely to be a problem in our sample. Nevertheless, we estimate each of the market effects models using Ordinary Least Squares (OLS) and find similar results.

Next, we investigate whether the decision to provide open calls is made opportunistically based on the expected market reaction to the disclosure. As mentioned earlier, no firms switch from open calls to closed calls during our sample period, suggesting that the decision to provide open calls is "sticky." However, firms could opportunistically shift their conference calls in or out of trading hours depending on the news they have to disclose. We find that over $80 \%$ of our sample firms host calls either always during trading hours or always during nontrading hours. Thus, the choice to provide calls during trading hours also appears to be a sticky policy choice. As an additional test, we estimate our market effects tests for only those firms that always held their calls during trading hours and the results are consistent with those reported earlier. Overall, we find little evidence that managers opportunistically choose the time and level of access to their calls based on the expected market reaction to the disclosure.

\footnotetext{
${ }^{27}$ An alternative approach to MLE is to estimate the market effects model with 2SLS using the fitted probabilities from the probit disclosure model as an instrumental variable (Greene 1998, Leuz and Verrecchia, 2000). This
} 
Finally, we consider whether open and closed calls differ in their information content. Measuring information content is problematic because we cannot directly measure what new information is released during the call or whether the information is better or worse than expected. As a proxy for the information content, we examine raw stock returns and squared stock returns during the call period. We find no significant difference in raw returns between open and closed calls, suggesting that there are no systematic differences in the type of news (good or bad) released between open and closed calls. We find significantly higher average squared returns for open calls than for closed calls, suggesting greater information content in open calls, contrary to what would be expected if managers are withholding information during open calls due to liability or proprietary information concerns. However, this measure is confounded by the amount of volatility in the stock price, which Tables 5 and 6 indicate is higher in the case of open calls. We separately include the raw return and the squared return as controls in the maximum likelihood estimation and find no significant differences in the results, suggesting that differences in information content are not driving the results.

\section{Summary and conclusions}

Recent innovations in information technology have enabled companies to provide all investors real-time access to conference calls that were previously accessible only by a select group of investment professionals. We investigate the determinants of the choice to provide open conference calls at a firm's quarterly earnings announcement. Our results indicate that firms providing open conference calls tend to have a greater number of stockholders (relative to firms of similar size), lower institutional ownership, lower analyst following, and higher average share turnover than firms providing calls to a more restricted audience ("closed" calls).

approach yields similar results for all analyses. 
Moreover, when firms with lower institutional ownership and lower analyst following do allow open access to their calls, they are less likely to make them available via webcast, an arguably broader information dissemination method. These findings are consistent with firms providing open conference calls to meet nonprofessional shareholders' demands to make information widely available.

Moreover, we find that firms with higher recorded intangible assets are less likely to provide open calls, consistent with firms having more complex financial information targeting their disclosures to more sophisticated users. Firms in industries with low R-squares from an annual ERC regression are also less likely to provide open calls, suggesting that firms with low financial statement informativeness are more likely to restrict the access of unsophisticated investors. However, our other proxy for financial statement informativeness, the book-to-price ratio, is not significantly related to the decision to provide open calls, possibly due to the fact that conference call firms tend to have relatively high market-to-book ratios (Tasker, 1998; Frankel, Johnson, and Skinner, 1999). We find that firms with greater revenue volatility and firms in high-tech industries are more likely to provide open calls, contrary to our prediction that firms with more complex business models would want their conference call disclosures filtered through sophisticated analysts and investors. Finally, we find no significant relation between the decision to provide open calls and employee demands for information.

The results from the determinants test must be interpreted with some caution due to the potential endogeneity between the decision to host open calls and the firm characteristics. However, these results are generally robust to a number of sensitivity checks. Results using lagged values of the firm characteristics are essentially the same, suggesting that the decision to host open conference calls is associated with firm characteristics in place before the decision was 
made. In addition, changes in determinants are generally not statistically different between open and closed call firms, indicating that the results are not driven by changes in firm characteristics after the decision to host open calls was made.

Next, we examine the impact that such calls have on trading behavior and price movements during the conference call period. Prior research finds that average trade size increases during conference calls, suggesting that larger investors trade during these calls (Frankel, Johnson, and Skinner, 1999). Our results suggest that open calls are associated with a greater percentage increase in small trades (trades of less than $\$ 10,000$ ), consistent with individual investors exploiting their opportunity to trade in real-time based on information released during open calls. We also find that open calls are associated with higher price volatility, but not with the level of trading volume. These results suggest that providing individual investors access to conference calls increases both the amount of informedness and consensus in the market.

Overall, our findings suggest that broadening access to information is a strategic decision made by managers. Providing wider access to disclosure not only enables individual investors to immediately trade based on the information, consistent with the SEC's desire to provide a "level playing field," but also increases price variability during the period. As new technologies continue to develop, managers will be faced with similar decisions regarding the costs and benefits of pursuing new avenues of information dissemination (e.g., e-mail alerts, real-time access to financial statements, etc.). Our findings shed some light on the possible factors that could influence such decisions and the potential impact of these decisions on the market. 


\section{References}

Bamber, L., Barron, O., Stober, T., 1997. Trading volume and different aspects of disagreement coincident with earnings announcements. The Accounting Review, 72(4), 575-597.

Bamber, L., Cheon, Y., 1995. Differential price and volume reactions to accounting earnings announcements. The Accounting Review, 70(3), 417-441.

Barron, O., 1995. Trading volume and belief revisions that differ among individual analysts. The Accounting Review, 70(4), 581-597.

Barron, O., Byard D., Enis C., 2001. Leveling the informational playing field. Working paper, Pennsylvania State University.

Barth, M., Kasznik, R., McNichols, M., 2001. Analyst coverage and intangible assets. Journal of Accounting Research, 39(1), 1-34.

Bhattacharya, N., 2001. Investors' trade size and trading responses around earnings announcements: An empirical investigation. The Accounting Review, 76(2), 221-244.

Biddle, G., Seow, G., 1990. The estimation and determinants of associations between returns and earnings: Evidence from cross-industry comparisons. Journal of Accounting, Auditing and Finance 6, 183-232.

Botosan, C., Harris, M., 2000. Motivations for a change in disclosure frequency and its consequences: An examination of voluntary quarterly segment disclosures. Journal of Accounting Research, 38(2), 329-353.

Bowen, R., Davis, A., Matsumoto, D., 2002. Do conference calls affect analysts' forecasts? The Accounting Review, 77(2), in press.

Bushee, B., Noe, C., 2000. Corporate disclosure practices, institutional investors, and stock return volatility. Journal of Accounting Research 38(Supplement).

Bushman, R., Gigler, F., Indjejikian, R., 1996. A model of two-tiered financial reporting. Journal of Accounting Research, 34(Supplement), 51-74.

Cready, W., 1988. Information value and investor wealth: The case of earnings announcements. Journal of Accounting Research, 26(1), 1-27.

Francis, J., Schipper, K., 1999. Have financial statements lost their relevance? Journal of Accounting Research, 37(2), 319-352.

Frankel, R., Johnson, M., Skinner, D., 1999. An empirical examination of conference calls as a voluntary disclosure medium. Journal of Accounting Research, 37(1), 133-150. 
Froot, K., Perold, A., Stein J., 1992. Shareholder trading practices and corporate investment horizons. Journal of Applied Corporate Finance (Summer), 42-58.

Frost, C., Pownall, G., 1994. Accounting disclosure practices in the United States and the United Kingdom. Journal of Accounting Research, 32(1), 75-102.

Greene, W., 1998, LIMDEP, Version 7.0: User's Manual. Econometric Software Inc, Plainview, NY.

Greene, W., 2000, Econometric Analysis, Fourth Edition. Prentice Hall, Saddle River, NJ.

Healy, P., Palepu, K., 2001. Information asymmetry, corporate disclosure, and the capital markets: A review of the empirical disclosure literature. Journal of Accounting and Economics, 31, 405-440.

Healy, P., Hutton, A., Palepu, K., 1999. Stock performance and intermediation changes surrounding sustained increases in disclosure. Contemporary Accounting Research, 16(3), 485-520.

Holthausen, R., Verrecchia, R., 1990. The effect of informedness and consensus on price and volume behavior. The Accounting Review, 65(1), 191-208.

Investor Relations Business Staff Reports (IRB Staff), 2000. Giving investors too much information could be a loaded gun for companies. Investor Relations Business, February 7 , $2000,1$.

Kennedy, P., 1998, A Guide to Econometrics, Fourth Edition, The MIT Press, Cambridge, MA.

Lang, M., Lundholm, R., 1993. Cross-sectional determinants of analyst ratings of corporate disclosures. Journal of Accounting Research, 31(2), 246-271.

Lee, C., 1992. Earnings news and small traders: An intraday analysis. Journal of Accounting and Economics, 15(3), 265-302

Lee, C., Radhakrishna, B., 2000. Inferring investor behavior: Evidence from TORQ data. Journal of Financial Markets, 3(2), 83-11.

Lev, B., Zarowin, P., 1999. The boundaries of financial reporting and how to extend them. Journal of Accounting Research, 37(2), 353-386.

Leuz, C., Verrecchia, R., 2000. The economic consequences of increased disclosure. Journal of Accounting Research 38(Supplement).

Maddala, G., 1986, Limited Dependent and Qualitative Variables in Econometrics, Econometric Society Monographs. 
Matsumoto, D., 2002. Management's incentives to avoid negative earnings surprises. The Accounting Review, 77(3), in press.

Miller, G., Piotroski, J., 2000. Forward-looking earnings statements: Determinants and market response. Working paper, Harvard University.

National Investor Relations Institute (NIRI), 1998. Survey of corporate disclosure practices among U.S. companies, July 1998.

National Investor Relations Institute (NIRI), 1999. On-line trading becoming way of life for investors, IR Update, October 1999, 16.

National Investor Relations Institute (NIRI), 2000a. Web disclosure practice is still unfolding. IR Update, February 2000, 18.

National Investor Relations Institute (NIRI), 2000b. IROs assess uses, value and challenge of technology. IR Update, June 2000, 16.

National Investor Relations Institute (NIRI), 2001. Webcasting survey. IR Update, February $2001,12$.

Puhani, P., 2000. The Heckman correction for sample selection and its critique: A short survey. Journal of Economic Surveys, 14, 53-68.

Reilly, M., 2000. Investor relations on the Internet takes on a new face. IR Update, National Investor Relations Institute, February 2000, 16-18.

Tasker, S., 1998. Bridging the information gap: Quarterly conference calls as a medium for voluntary disclosure. Review of Accounting Studies, 3(1 \& 2), 137-167.

Thompson, L., 2000. Most corporate conference calls are now open to individual investors and the media. Executive Alert, National Investor Relations Institute, February 29, 2000.

Verrecchia, R., 2001. Essays on disclosure. Journal of Accounting and Economics, forthcoming.

Vinzant, C., 2001. Keeping an ear on Wall St; Corporate webcasts earn a growing audience of investors. Washington Post, June 14, E01.

Wang, J., 1993. A model of intertemporal asset prices under asymmetric information. Review of Economic Studies, 60(2), 249-282.

Wiggins, J., 1991. Empirical tests of the bias and efficiency of the extreme-value variance estimator for common stocks. Journal of Business, 64(3), 417-432. 
Figure 1

Timeline depiction of measurement periods ${ }^{1}$

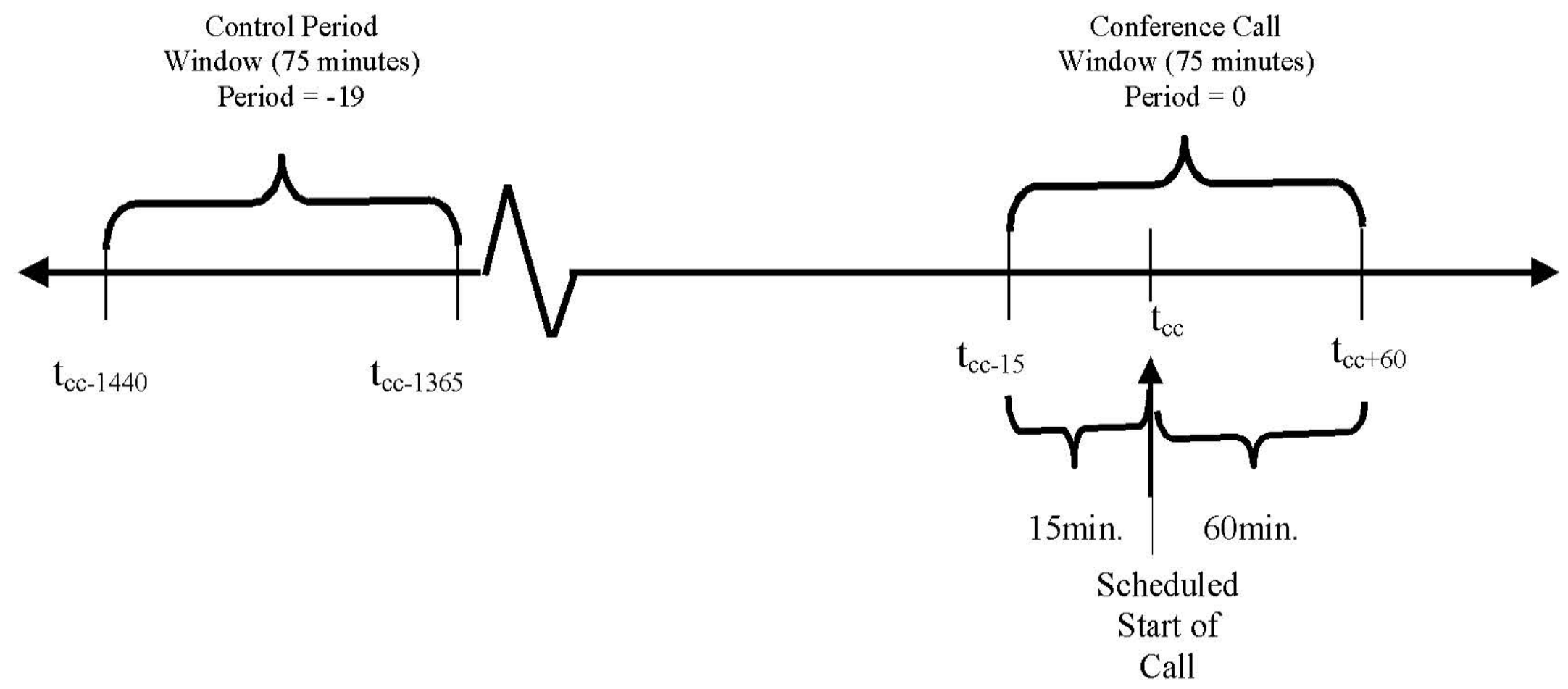

${ }^{1}$ The conference call period is defined based on the period used in Frankel, Johnson, and Skinner (1999) 
Table 1

Descriptive statistics on open conference calls from BestCalls.com database

\begin{tabular}{lccc}
\multicolumn{5}{l}{ Panel A: Open conference calls by type and by live vs. replay } \\
\hline Stated Reason for Call & All Calls & Live Calls & Replayed Calls \\
\hline Earnings Announcement (EA) & 8,789 & 4,158 & 4,631 \\
Special Conference & 318 & 154 & 164 \\
Analyst Interview & 134 & 3 & 131 \\
Shareholder Meeting & 71 & 31 & 40 \\
Management Interview & 318 & 128 & 190 \\
Business or Product News & 178 & 80 & 98 \\
Other & 81 & 31 & 50 \\
Total Calls & 9,889 & 4,585 & 5,304 \\
\hline
\end{tabular}

Panel B: Open conference calls by method of access ${ }^{2}$

\begin{tabular}{|c|c|c|c|c|c|}
\hline Method of access & All & & All E & alls & Live EA Calls \\
\hline Webcast & $8,431(85.3 \%)$ & & $7,390(84.1 \%)$ & & $3,483(83.7 \%)$ \\
\hline Company website & & $573(6.8 \%)$ & & $535(7.2 \%)$ & $242(6.9 \%)$ \\
\hline Vcall & & $4,241(50.3 \%)$ & & $3,798(51.4 \%)$ & $1,869(53.7 \%)$ \\
\hline StreetFusion & & $1,110(13.2 \%)$ & & $1,096(14.8 \%)$ & $458(13.1 \%)$ \\
\hline Other provider & & $2,507(29.7 \%)$ & & $1,961(26.5 \%)$ & $914(26.2 \%)$ \\
\hline Telephone-only & $1,458(14.7 \%)$ & & $1,399(15.9 \%)$ & & $675(16.3 \%)$ \\
\hline Toll-free number & & $840(57.6 \%)$ & & $803(57.4 \%)$ & $314(46.5 \%)$ \\
\hline Toll access only & & $618(42.4 \%)$ & & $596(42.6 \%)$ & $361(53.5 \%)$ \\
\hline
\end{tabular}

${ }^{1}$ This table includes all conference calls listed by BestCall.com that were held between 3/1/1999 and 6/30/2000. Open conference calls are defined as calls that provide unlimited access to the call. Live calls provide real-time access, whereas replayed calls are recorded and made available after the live broadcast is over. ${ }^{2}$ Webcast calls are provided via the Internet and may also be simultaneously provided via telephone. Telephone-only calls are only available by calling into either a toll-free or toll access number. Vcall and StreetFusion are companies that broadcast webcasts from their website. 
Table 2

Definitions of variables

\begin{tabular}{|c|c|c|c|}
\hline \multicolumn{4}{|c|}{ Panel A: Hypothesized Determinants of Open Conference Calls } \\
\hline & Variable & & Predicted \\
\hline Variable & Name & Definition/ Source $^{1}$ & Association \\
\hline Number of shareholders & $\begin{array}{l}\text { NOWN } \\
\text { (LNOWN) }\end{array}$ & $\begin{array}{l}\text { (Log of) Compustat item \#100 at end of fiscal year - (Log of) mean number of shareholders in } \\
\text { same size decile as firm }\end{array}$ & Positive \\
\hline Institutional ownership & PIH & Shares held by institutions from Spectrum $\div$ total shares from CRSP at end of year & Negative \\
\hline Analyst following & NAL & Largest monthly number of analyst earnings estimates during year (IBES) & Negative \\
\hline Mean share turnover & MTURN & $\begin{array}{l}\text { Mean monthly trading volume divided by average shares outstanding over the } 12 \text { month period } \\
\text { January } 1999 \text { - December } 1999 \text { (CRSP) }\end{array}$ & Positive \\
\hline Volatility of quarterly revenues & VREV & Standard deviation of quarterly revenue over 16 quarters (Quarterly Compustat item \# 2) & Negative \\
\hline Book-to-price ratio & $\mathrm{BP}$ & Book value (Compustat item \#60) $\div$ Market value (Compustat item \# $25 \times \# 24)$ & Positive \\
\hline Industry ERC R-square & IRSQ & $\begin{array}{l}\text { R-square from a regression of market adjusted returns on annual change in earnings and level of } \\
\text { earnings (both deflated by prior price) estimated by 2-digit SIC over the fiscal years 1997-1999 }\end{array}$ & Positive \\
\hline Percentage of intangible assets & INTAN & Intangible assets (Compustat item $\# 33$ ) $\div$ Total assets (Compustat item \#6) & Negative \\
\hline $\begin{array}{l}\text { Membership in high-tech } \\
\text { industry }\end{array}$ & DHTECH & $\begin{array}{l}\text { SIC Codes: } 2833-36,3612-13,3621-29,3651-52,3661-69,3671-2,3674,3695,4812-22,4832- \\
99,7370-79\end{array}$ & Negative \\
\hline Number of employees & $\begin{array}{l}\text { NEMP } \\
\text { (LNEMP) }\end{array}$ & $\begin{array}{l}\text { (Log of) Compustat item \#29 at end of fiscal year - ( Log of) mean number of employees in } \\
\text { same size decile as firm }\end{array}$ & Positive \\
\hline Firm size (control variable) & $\begin{array}{l}\text { MV } \\
\text { (LMV) }\end{array}$ & (Log of) market value of equity (Compustat item \# $25 \times \# 24$ ) & $?$ \\
\hline Age of firm (control variable) & $\begin{array}{l}\text { TIME } \\
\text { (LTIME) }\end{array}$ & ( $\log$ of) the number of months listed on CRSP & $?$ \\
\hline \multicolumn{4}{|c|}{ Panel B: Hypothesized Effects of Open Conference Calls } \\
\hline Variable & $\begin{array}{l}\text { Variable } \\
\text { Name }\end{array}$ & Definition/ Source & $\begin{array}{c}\text { Predicted } \\
\text { Association }\end{array}$ \\
\hline Percentage of small trades & SMTRADE & Number of trades less than $\$ 10,000^{2} \div$ total number of trades during 75 -minute period (TAQ) $)^{3}$ & Positive \\
\hline Maximum price change & HI_LO & (High price - low price) $\div$ low price during 75 -minute period (TAQ) & Positive \\
\hline Coefficient of variation & CVPRICE & Standard deviation of price $\div$ mean price during 75 -minute period $(\mathrm{TAQ})$ & Positive \\
\hline Trading volume & TVOL & Total trading volume in shares during 75 -minute period (TAQ) & Positive \\
\hline Percentage of medium trades & MDTRADE & $\begin{array}{l}\text { Number of trades between } \$ 10,000 \text { and } \$ 50,000 \div \text { total number of trades during } 75 \text {-minute } \\
\text { period (TAQ) }\end{array}$ & $?$ \\
\hline Percentage of large trades & LGTRADE & Number of trades greater than $\$ 50,000 \div$ total number of trades during 75 -minute period (TAQ) & ? \\
\hline
\end{tabular}


Table 3

Descriptive statistics on firm characteristics of conference call firms

Panel A: Open vs. closed conference call firms ${ }^{1}$

\begin{tabular}{lcccc}
\hline & \multicolumn{2}{c}{ Open Call Firms $(\mathrm{n}=1,799)$} & \multicolumn{2}{c}{ Closed Call firms $(\mathrm{n}=1,475)$} \\
& Mean & Median & -0.275 & $-2.267^{* *}$ \\
\hline NOWN & 2 & -1.967 & $0.421^{* *}$ & $0.431^{* *}$ \\
PIH & 0.273 & 0.335 & $4.017^{*}$ & $2.000^{* *}$ \\
NAL & 0.359 & 1.000 & $0.123^{* *}$ & $0.077^{* *}$ \\
MTURN & 3.594 & 0.113 & $1.185^{* *}$ & $0.237^{* *}$ \\
VREV & 0.184 & 0.329 & $0.597^{* *}$ & $0.470^{* *}$ \\
BP & 1.973 & 0.311 & 0.291 & 0.194 \\
IRSQ & 0.474 & 0.209 & $0.126^{* *}$ & $0.035^{* *}$ \\
INTAN & 0.296 & 0.009 & $0.130^{* *}$ & 0.000 \\
DHTECH & 0.095 & 0.000 & -0.086 & $-0.251^{*}$ \\
NEMP & 0.196 & -0.126 & 4125.626 & 474.232 \\
MV & 0.062 & 465.191 & $181.355^{* *}$ & $93.000^{* *}$ \\
TIME & 4604.679 & 82.000 &
\end{tabular}

** $\left({ }^{*}\right)$ Significantly different from mean or median of open call firms at the $0.01(0.05)$ level

Panel B: Webcast vs. telephone-only open conference call firms ${ }^{3}$

\begin{tabular}{lcrcc}
\hline & \multicolumn{2}{c}{ Webcast Firms $(\mathrm{n}=1,575)$} & \multicolumn{2}{c}{ Telephone-only firms $(\mathrm{n}=224)$} \\
& Mean & Median & -0.126 & Mean \\
\hline NOWN & 0.330 & -1.960 & $0.404^{* *}$ & -2.061 \\
PIH & 0.352 & 0.318 & 3.750 & $0.406^{* *}$ \\
NAL & 3.572 & 1.000 & $0.150^{* *}$ & $0.098^{*}$ \\
MTURN & 0.188 & 0.115 & 1.560 & $0.285^{*}$ \\
VREV & 2.031 & 0.340 & 0.515 & 0.348 \\
BP & 0.468 & 0.305 & $0.325^{*}$ & $0.263^{*}$ \\
IRSQ & 0.286 & 0.194 & 0.103 & 0.021 \\
INTAN & 0.094 & 0.008 & $0.121^{* *}$ & 0.000 \\
DHTECH & 0.206 & 0.000 & 0.219 & -0.166 \\
NEMP & 0.400 & -0.120 & $2390.989^{*}$ & 352.218 \\
MV & 4919.515 & 473.285 & $175.821^{*}$ & $103.000^{* *}$ \\
TIME & 141.949 & 79.000 & &
\end{tabular}

** (*) Significantly different from mean or median of webcast firms at the $0.01(0.05)$ level 
Table 3 (continued)

Descriptive statistics on firm characteristics of conference call firms

Panel C: Correlation matrix of firm characteristics ${ }^{4}$

\begin{tabular}{lccccccccccccc}
\hline & LNOWN & PIH & NAL & MTURN & VREV & BP & IRSQ & INTAN & DHTECH & LNEMP & LMV & LTIME \\
\hline LNOWN & 1.00 & $-0.06^{*}$ & $-0.07^{*}$ & -0.01 & $0.06^{*}$ & $-0.08^{*}$ & -0.03 & $-0.11^{*}$ & 0.02 & -0.02 & $0.04^{*}$ & $0.12^{*}$ \\
PIH & $-0.07^{*}$ & 1.00 & $0.25^{*}$ & $-0.24^{*}$ & $-0.28^{*}$ & $0.18^{*}$ & $0.10^{*}$ & $0.04^{*}$ & $-0.18^{*}$ & -0.02 & $0.28^{*}$ & $0.53^{*}$ \\
NAL & $-0.07^{*}$ & $0.24^{*}$ & 1.00 & $0.04^{*}$ & $-0.11^{*}$ & $-0.06^{*}$ & -0.02 & $0.05^{*}$ & 0.02 & $0.06^{*}$ & $0.35^{*}$ & $0.12^{*}$ \\
MTURN & -0.02 & $-0.12^{*}$ & $0.12^{*}$ & 1.00 & $0.24^{*}$ & $-0.28^{*}$ & $-0.10^{*}$ & $-0.06^{*}$ & $0.23^{*}$ & $0.04^{*}$ & $0.14^{*}$ & $-0.34^{*}$ \\
VREV & $0.04^{*}$ & $-0.37^{*}$ & $-0.16^{*}$ & $0.33^{*}$ & 1.00 & $-0.12^{*}$ & $-0.08^{*}$ & 0.02 & 0.03 & -0.01 & $-0.07^{*}$ & $-0.28^{*}$ \\
BP & $-0.08^{*}$ & $0.23^{*}$ & $-0.05^{*}$ & $-0.40^{*}$ & $-0.20^{*}$ & 1.00 & $0.13^{*}$ & $0.10^{*}$ & $-0.24^{*}$ & $-0.05^{*}$ & $-0.39^{*}$ & $0.13^{*}$ \\
IRSQ & -0.02 & $0.15^{*}$ & -0.01 & $-0.12^{*}$ & $-0.11^{*}$ & $0.21^{*}$ & 1.00 & -0.02 & $-0.36^{*}$ & $-0.08^{*}$ & $-0.14^{*}$ & $0.12^{*}$ \\
INTAN & $-0.11^{*}$ & $0.11^{*}$ & $0.11^{*}$ & $-0.10^{*}$ & $-0.04^{*}$ & $0.14^{*}$ & -0.01 & 1.00 & -0.01 & $0.16^{*}$ & -0.01 & $-0.04^{*}$ \\
DHTECH & 0.02 & $-0.16^{*}$ & 0.02 & $0.27^{*}$ & $0.13^{*}$ & $-0.29^{*}$ & $-0.48^{*}$ & $-0.05^{*}$ & 1.00 & $0.08^{*}$ & $0.08^{*}$ & $-0.20^{*}$ \\
LNEMP & -0.01 & -0.01 & $0.06^{*}$ & $0.06^{*}$ & $-0.05^{*}$ & $-0.04^{*}$ & $-0.09^{*}$ & $0.19^{*}$ & $0.08^{*}$ & 1.00 & 0.00 & $-0.06^{*}$ \\
LMV & 0.03 & $0.31^{*}$ & $0.34^{*}$ & $0.16^{*}$ & $-0.16^{*}$ & $-0.37^{*}$ & $-0.11^{*}$ & 0.00 & $0.08^{*}$ & -0.02 & 1.00 & $0.23^{*}$ \\
LTIME & $0.13^{*}$ & $0.50^{*}$ & $0.10^{*}$ & $-0.30^{*}$ & $-0.43^{*}$ & $0.22^{*}$ & $0.19^{*}$ & $0.04^{*}$ & $-0.20^{*}$ & $-0.08^{*}$ & $0.21^{*}$ & 1.00 \\
\hline
\end{tabular}

* Significantly different from zero at the 0.05 level

${ }^{1}$ Open conference calls are defined as calls that provide unlimited access to the call. These calls are listed on the BestCalls.com database. Closed conference calls are defined as calls that provide restricted access to selected parties only. These calls are listed on the First Call database and not on the BestCalls.com database.

${ }^{2}$ See Table 2 for variable definitions.

${ }^{3}$ Webcast calls are provided via the Internet and may also be simultaneously provided via telephone. Telephoneonly calls are only available by calling into either a toll-free or toll access number. All of these calls are open conference calls.

${ }^{4}$ Pearson (Spearman) correlation coefficients are above (below) the diagonal. 
Table 4

Analysis of the determinants of the choice to provide open conference calls

\begin{tabular}{|c|c|c|c|c|c|}
\hline $\begin{array}{l}\text { Prob(Open or } \\
+\beta_{7} I R S Q \\
\end{array}$ & - & $\begin{array}{l}\beta_{1} L N O W N_{i} \\
\beta_{9} D H T E C H \\
\end{array}$ & $\begin{array}{r}+\beta_{3} N A L \\
V E M P_{i}+\beta \\
\end{array}$ & $\begin{array}{l}+\beta_{5} \operatorname{VREV} V_{i}+ \\
\left.I M E_{i}+\varepsilon_{i}\right) \\
\end{array}$ & \\
\hline & & & & Prob & \\
\hline Variable & & $\begin{array}{c}\text { Coefficient } \\
\text { (p-value) }\end{array}$ & $\begin{array}{c}\text { Marginal }^{3} \\
\text { Impact }\end{array}$ & $\begin{array}{c}\text { Coefficient } \\
\text { (p-value) }\end{array}$ & $\begin{array}{c}\text { Marginal } \\
\text { Impact }\end{array}$ \\
\hline INTERCEPT $^{4}$ & & $\begin{array}{c}0.306 \\
(0.187)\end{array}$ & & $\begin{array}{c}.376 \\
(0.008)\end{array}$ & \\
\hline LNOWN & + & $\begin{array}{c}0.054 \\
(0.036)\end{array}$ & 0.031 & $\begin{array}{c}0.119 \\
(0.219)\end{array}$ & 0.030 \\
\hline PIH & - & $\begin{array}{l}-1.150 \\
(0.000)\end{array}$ & -0.129 & $\begin{array}{l}-1.560 \\
(0.011)\end{array}$ & -0.077 \\
\hline NAL & - & $\begin{array}{l}-0.051 \\
(0.004)\end{array}$ & -0.064 & $\begin{array}{l}-0.077 \\
(0.039)\end{array}$ & -0.043 \\
\hline MTURN & + & $\begin{array}{c}1.973 \\
(0.000)\end{array}$ & 0.067 & $\begin{array}{c}0.242 \\
(0.645)\end{array}$ & 0.004 \\
\hline VREV & - & $\begin{array}{c}0.051 \\
(0.014)\end{array}$ & 0.006 & $\begin{array}{l}-0.062 \\
(0.354)\end{array}$ & -0.003 \\
\hline BP & + & $\begin{array}{c}0.009 \\
(0.483)\end{array}$ & 0.001 & $\begin{array}{c}0.119 \\
(0.185)\end{array}$ & 0.008 \\
\hline IRSQ & + & $\begin{array}{c}0.249 \\
(0.066)\end{array}$ & 0.020 & $\begin{array}{l}-0.014 \\
(0.958)\end{array}$ & -0.000 \\
\hline INTAN & - & $\begin{array}{l}-0.921 \\
(0.000)\end{array}$ & -0.036 & $\begin{array}{l}-0.293 \\
(0.537)\end{array}$ & -0.005 \\
\hline DHTECH & - & $\begin{array}{c}0.283 \\
(0.011)\end{array}$ & 0.006 & $\begin{array}{c}0.331 \\
(0.164)\end{array}$ & 0.013 \\
\hline LNEMP & + & $\begin{array}{l}-0.037 \\
(0.366)\end{array}$ & -0.009 & $\begin{array}{c}0.170 \\
(0.593)\end{array}$ & 0.019 \\
\hline LMV & $?$ & $\begin{array}{c}0.022 \\
(0.335)\end{array}$ & 0.014 & $\begin{array}{c}0.176 \\
(0.000)\end{array}$ & 0.049 \\
\hline LTIME & ? & $\begin{array}{l}-0.023 \\
(0.613)\end{array}$ & -0.008 & $\begin{array}{l}-0.196 \\
(0.035)\end{array}$ & -0.032 \\
\hline$\chi^{2}$-statistic & & $\begin{array}{c}217.271 \\
(0.000)\end{array}$ & & $\begin{array}{l}49.875 \\
(0.000)\end{array}$ & \\
\hline Pseudo- $\mathrm{R}^{2}$ & & 0.178 & & 0.052 & \\
\hline
\end{tabular}

${ }^{1}$ This regression models the probability of providing an open conference call instead of a closed call. Open call firms provide unlimited access ( 1,799 firms), whereas closed call firms provide restricted access (1,475 firms).

${ }^{2}$ This regression models the probability of providing an open call via a webcast instead of by telephone only. Webcast firms provide access via the Internet (1,575 firms), where telephone-only firms provide access via a tollfree or toll access number only (224 firms).

${ }^{3}$ The marginal impact represents the change in the probability of providing an open (or webcast) call given a change in the independent variable across its interquartile range (i.e. from the $25^{\text {th }}$ to the $75^{\text {th }}$ percentile). For the indicator variable DHTECH, the marginal impact is the difference in probability when the variable equals one versus when it equals zero, evaluated at the mean of the other variables.

${ }^{4}$ See Table 2 for variable definitions. 
Table 5

Descriptive statistics on the market effects of conference calls

Panel A: Comparison of means and medians between open and closed conference calls ${ }^{1}$

\begin{tabular}{|c|c|c|c|c|c|c|c|c|c|c|c|c|c|}
\hline & \multirow[b]{2}{*}{$\mathrm{N}$} & \multicolumn{2}{|c|}{ SMTRADE $^{2}$} & \multicolumn{2}{|c|}{ MDTRADE } & \multicolumn{2}{|c|}{ LGTRADE } & \multicolumn{2}{|c|}{ HI LO } & \multicolumn{2}{|c|}{ CVPRC } & \multicolumn{2}{|c|}{ LTVOL } \\
\hline & & Mean & Median & Mean & Median & Mean & Median & Mean & Median & Mean & Median & Mean & Median \\
\hline Open Calls & 1,463 & 0.663 & 0.667 & 0.250 & 0.252 & 0.086 & 0.093 & 0.043 & 0.027 & 0.011 & 0.008 & 13.354 & 13.344 \\
\hline Closed Calls & 1,713 & 0.579 & 0.556 & 0.286 & 0.294 & 0.135 & 0.169 & 0.030 & 0.019 & 0.008 & 0.006 & 13.646 & 13.618 \\
\hline test statistic ${ }^{3}$ & & 10.450 & 8.420 & 5.970 & 5.230 & 10.460 & 7.590 & 7.140 & 7.800 & 8.730 & 7.440 & 3.840 & 2.380 \\
\hline p-value & & 0.001 & 0.001 & 0.001 & 0.001 & 0.001 & 0.001 & 0.001 & 0.001 & 0.001 & 0.001 & 0.001 & 0.0171 \\
\hline
\end{tabular}

Panel B: Comparison of means and medians between webcast and telephone-only conference calls ${ }^{4}$

\begin{tabular}{|c|c|c|c|c|c|c|c|c|c|c|c|c|c|}
\hline & \multirow[b]{2}{*}{$\mathrm{N}$} & \multicolumn{2}{|c|}{ SMTRADE } & \multicolumn{2}{|c|}{ MDTRADE } & \multicolumn{2}{|c|}{ LGTRADE } & \multicolumn{2}{|c|}{$\mathrm{HI} \mathrm{LO}$} & \multicolumn{2}{|c|}{ CVPRC } & \multicolumn{2}{|c|}{ LTVOL } \\
\hline & & Mean & Median & Mean & Median & Mean & Median & Mean & Median & Mean & Median & Mean & Median \\
\hline Webcast Calls & 1,302 & 0.666 & 0.667 & 0.249 & 0.250 & 0.085 & 0.091 & 0.043 & 0.027 & 0.011 & 0.008 & 13.352 & 13.313 \\
\hline Phone-only Calls & 161 & 0.643 & 0.637 & 0.258 & 0.262 & 0.099 & 0.113 & 0.042 & 0.025 & 0.011 & 0.007 & 13.372 & 13.780 \\
\hline test statistic ${ }^{3}$ & & 1.190 & 2.250 & 0.590 & 0.760 & 1.340 & 2.680 & 0.210 & 1.010 & 0.120 & 2.080 & 0.110 & 1.430 \\
\hline p-value & & 0.234 & 0.135 & 0.543 & 0.447 & 0.181 & 0.008 & 0.807 & 0.312 & 0.919 & 0.038 & 0.911 & 0.153 \\
\hline
\end{tabular}

${ }^{1}$ Open conference calls are defined as calls that provide unlimited access to the call. Closed calls are defined as calls that provide restricted access.

${ }^{2}$ See Table 2 for variable definitions.

${ }^{3}$ The "test statistic" is a t-statistic for the means and a z-statistic for the medians. We use the t-statistic for unequal variances if the folded F-test indicates it is appropriate; otherwise we use the t-statistic for equal variances. All p-values are two-tailed.

${ }^{4}$ Webcast conference calls are provided via the Internet and may also be simultaneously provided via telephone. Telephone-only calls are only available by calling into either a toll-free or toll access number. 
Table 6

Changes analysis of the market effects of providing open conference calls

Panel A: Tests of differences in means and medians between open and closed conference calls ${ }^{1}$

\begin{tabular}{|c|c|c|c|c|c|c|c|c|c|c|c|c|c|}
\hline & \multirow[b]{2}{*}{$\mathrm{N}$} & \multicolumn{2}{|c|}{$\triangle \mathrm{SMTRADE}^{2}$} & \multicolumn{2}{|c|}{$\triangle$ MDTRADE } & \multicolumn{2}{|c|}{$\triangle \mathrm{LGTRADE}$} & \multicolumn{2}{|c|}{$\Delta \mathrm{HI} \mathrm{LO}$} & \multicolumn{2}{|c|}{$\triangle \mathrm{CVPRC}$} & \multicolumn{2}{|c|}{$\triangle \mathrm{LTVOL}$} \\
\hline & & Mean & Median & Mean & Median & Mean & Median & Mean & Median & Mean & Median & Mean & Median \\
\hline Open Calls & 1,463 & 0.101 & 0.351 & 0.164 & 0.421 & 0.259 & 0.300 & 0.017 & 0.008 & 0.003 & 0.002 & 0.641 & 0.572 \\
\hline Closed Calls & 1,713 & 0.014 & 0.286 & 0.158 & 0.448 & 0.221 & 0.357 & 0.011 & 0.005 & 0.002 & 0.001 & 0.655 & 0.622 \\
\hline test statistic ${ }^{3}$ & & 2.590 & 2.670 & 0.180 & 0.680 & 1.210 & 1.200 & 3.460 & 4.450 & 3.090 & 3.670 & 0.280 & 0.750 \\
\hline p-value & & 0.010 & 0.008 & 0.861 & 0.499 & 0.223 & 0.231 & 0.001 & 0.001 & 0.003 & 0.001 & 0.779 & 0.455 \\
\hline
\end{tabular}

Panel B: Tests of differences in means and medians between webcast and telephone-only conference calls ${ }^{4}$

\begin{tabular}{|c|c|c|c|c|c|c|c|c|c|c|c|c|c|}
\hline & \multirow[b]{2}{*}{$\mathrm{N}$} & \multicolumn{2}{|c|}{$\triangle \mathrm{SMTRADE}$} & \multicolumn{2}{|c|}{$\triangle \mathrm{MDTRADE}$} & \multicolumn{2}{|c|}{$\triangle \mathrm{LGTRADE}$} & \multicolumn{2}{|c|}{$\Delta \mathrm{HI} L \mathrm{LO}$} & \multicolumn{2}{|c|}{$\triangle \mathrm{CVPRC}$} & \multicolumn{2}{|c|}{$\triangle \mathrm{LTVOL}$} \\
\hline & & Mean & Median & Mean & Median & Mean & Median & Mean & Median & Mean & Median & Mean & Median \\
\hline Webcast Calls & 1,302 & 0.106 & 0.354 & 0.105 & 0.421 & 0.248 & 0.250 & 0.017 & 0.008 & 0.003 & 0.002 & 0.628 & 0.593 \\
\hline Phone-only Calls & 161 & 0.056 & 0.333 & 0.182 & 0.438 & 0.341 & 0.500 & 0.018 & 0.009 & 0.004 & 0.002 & 0.754 & 0.832 \\
\hline test statistic ${ }^{3}$ & & 0.660 & 0.580 & 0.230 & 0.260 & 1.520 & 1.600 & 0.370 & 0.093 & 0.100 & 1.240 & 1.120 & 1.600 \\
\hline p-value & & 0.816 & 0.565 & 0.829 & 0.795 & 0.131 & 0.111 & 0.714 & 0.926 & 0.915 & 0.214 & 0.245 & 0.111 \\
\hline
\end{tabular}

${ }^{1}$ Open conference calls are defined as calls that provide unlimited access to the call. Closed calls are defined as calls that provide restricted access.

${ }^{2}$ Except for $\triangle$ SMTRADE, $\triangle$ MDTRADE and $\triangle$ LGTRADE, these variables are the difference between the value of the variable in the conference call period (see Table 2 for variable definitions) and the value of the variable in the control period one day earlier (see Figure 1 for a timeline). The $\triangle$ SMTRADE variable is defined as the number of small trades in the call period minus the number of small trades in the control period, divided by the number of small trades in the call period. $\triangle$ MDTRADE and $\triangle \mathrm{LGTRADE}$ are defined analogously.

${ }^{3}$ The "test statistic" is a t-statistic for the means and a z-statistic for the medians. We use the t-statistic for unequal variances if the folded F-test indicates it is appropriate; otherwise we use the t-statistic for equal variances. All p-values are two-tailed.

${ }^{4}$ Webcast conference calls are provided via the Internet and may also be simultaneously provided via telephone. Telephone-only calls are only available by calling into either a toll-free or toll access number. 
Table 7

Maximum likelihood estimation of the market effects of providing open conference calls ${ }^{1}$

\begin{tabular}{|c|c|c|c|c|c|c|}
\hline \multicolumn{7}{|c|}{ Panel A: Levels analysis } \\
\hline Variable $^{2}$ & SMTRADE & MDTRADE & LGTRADE & HI_LO & CVPRC & LTVOL \\
\hline \multirow[t]{2}{*}{ INTERCEPT } & 1.1950 & -0.0414 & -0.1711 & 0.0583 & 0.0122 & 8.1317 \\
\hline & 0.000 & $(0.010)$ & 0.000 & 0.000 & 0.000 & 0.000 \\
\hline \multirow[t]{2}{*}{ OCALL } & 0.0209 & -0.0040 & -0.0145 & 0.0053 & 0.0006 & 0.0867 \\
\hline & $(0.010)$ & $(0.503)$ & $(0.004)$ & $(0.002)$ & $(0.002)$ & $(0.122)$ \\
\hline \multirow[t]{2}{*}{ LNOWN } & 0.0111 & -0.0091 & -0.0002 & 0.0012 & 0.0000 & 0.0133 \\
\hline & $(0.000)$ & 0.000 & $(0.924)$ & $(0.019)$ & $(0.658)$ & $(0.497)$ \\
\hline \multirow[t]{2}{*}{ MTURN } & 0.0431 & 0.0359 & -0.0542 & 0.0792 & 0.0086 & 3.6880 \\
\hline & $(0.268)$ & $(0.165)$ & $(0.015)$ & 0.000 & 0.000 & 0.000 \\
\hline \multirow[t]{2}{*}{$\mathrm{PIH}$} & -0.3103 & 0.1712 & 0.1329 & -0.0307 & -0.0048 & 1.4055 \\
\hline & 0.000 & 0.000 & 0.000 & 0.000 & 0.000 & 0.000 \\
\hline \multirow[t]{2}{*}{$\mathrm{BP}$} & 0.0051 & -0.0029 & -0.0018 & -0.0001 & 0.0000 & -0.0427 \\
\hline & $(0.011)$ & $(0.032)$ & $(0.574)$ & $(0.626)$ & $(0.296)$ & $(0.001)$ \\
\hline \multirow[t]{2}{*}{ LMV } & -0.0736 & 0.0350 & 0.0396 & -0.0029 & -0.0006 & 0.6633 \\
\hline & 0.000 & 0.000 & 0.000 & 0.000 & 0.000 & 0.000 \\
\hline \multicolumn{7}{|c|}{ Panel B: Changes Analysis } \\
\hline Variable & $\triangle$ SMTRADE $^{3}$ & $\triangle$ MDTRADE & $\triangle \mathrm{LGTRADE}$ & $\triangle \mathrm{HI} \mathrm{LO}$ & $\triangle \mathrm{CVPRC}$ & $\triangle \mathrm{LTVOL}$ \\
\hline \multirow[t]{2}{*}{ INTERCEPT } & -0.0404 & 1.4640 & 0.2787 & 0.0173 & 0.0026 & 1.4364 \\
\hline & $(0.636)$ & 0.000 & 0.000 & 0.000 & 0.000 & 0.000 \\
\hline \multirow[t]{2}{*}{ OCALL } & 0.0775 & 0.0477 & -0.0056 & 0.0021 & 0.0003 & 0.0596 \\
\hline & $(0.012)$ & $(0.325)$ & $(0.803)$ & $(0.073)$ & $(0.125)$ & $(0.329)$ \\
\hline \multirow[t]{2}{*}{ LNOWN } & -0.0123 & -0.0130 & -0.0062 & 0.0002 & 0.0000 & -0.0169 \\
\hline & $(0.249)$ & $(0.026)$ & $(0.429)$ & $(0.519)$ & $(0.679)$ & $(0.260)$ \\
\hline \multirow[t]{2}{*}{ MTURN } & 0.3732 & -0.2010 & 0.2833 & 0.0269 & 0.0032 & 0.3788 \\
\hline & $(0.001)$ & $(0.000)$ & $(0.000)$ & 0.000 & 0.000 & $(0.037)$ \\
\hline \multirow[t]{2}{*}{$\mathrm{PIH}$} & -0.1908 & -0.0418 & 0.1871 & -0.0114 & -0.0010 & 0.4116 \\
\hline & $(0.135)$ & $(0.533)$ & $(0.036)$ & $(0.006)$ & $(0.217)$ & $(0.015)$ \\
\hline \multirow[t]{2}{*}{$\mathrm{BP}$} & -0.0013 & -0.0001 & -0.0046 & -0.0001 & 0.0000 & -0.0149 \\
\hline & $(0.951)$ & $(0.994)$ & $(0.511)$ & $(0.898)$ & $(0.911)$ & $(0.375)$ \\
\hline \multirow[t]{2}{*}{ LMV } & 0.0219 & -0.0735 & -0.0134 & -0.0007 & -0.0001 & -0.0484 \\
\hline & $(0.052)$ & 0.000 & $(0.086)$ & $(0.056)$ & $(0.258)$ & $(0.001)$ \\
\hline
\end{tabular}

${ }^{1}$ Results reported are from a maximum likelihood estimation of the effects of open conference calls (and control variables) on the market effects variable shown at the top of each column. The model was estimated jointly with a model of the determinants of open conference calls identical to the model in Table 4 (results not reported). Coefficients and two-sided p-values (in parentheses) from each model are reported in the columns below.

${ }^{2}$ OCALL is an indicator variable equal to one if the firm hosts an open conference call and zero otherwise. In both sets of analyses, the coefficient on OCALL is predicted to be positive in the SMTRADE, HI_LO, CVPRC, and LTVOL model. We make no predictions for OCALL in the MDTRADE and LGTRADE models or for any of the control variables. Table 2 provides definitions of the remaining variables.

${ }^{3}$ Except for $\triangle$ SMTRADE, $\triangle$ MDTRADE and $\triangle$ LGTRADE, these variables are the difference between the value of the variable in the conference call period (see Table 2 for variable definitions) and the value of the variable in the control period one day earlier (see Figure 1 for a timeline). The $\triangle$ SMTRADE variable is defined as the number of small trades in the call period minus the number of small trades in the control period, divided by the number of small trades in the call period. $\triangle$ MDTRADE and $\triangle$ LGTRADE are defined analogously. 